Review

\title{
Health care system in Saudi Arabia: an overview
}

M. Almalki, ${ }^{12}$ G. Fitzgerald ${ }^{2}$ and M. Clark ${ }^{2}$

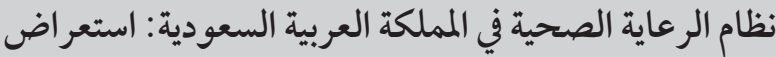

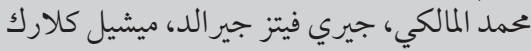

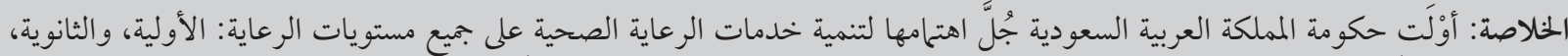

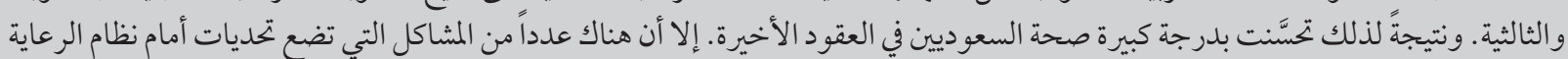

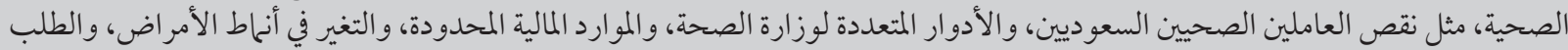

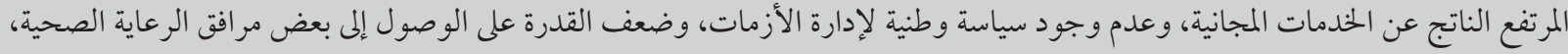

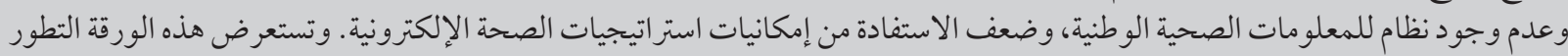

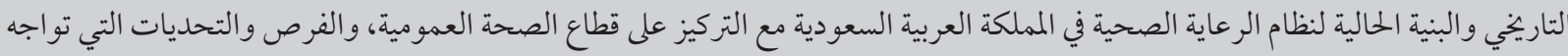
نظام الرعاية الصحية السعودي.

ABSTRACT The government of Saudi Arabia has given high priority to the development of health care services at all levels: primary, secondary and tertiary. As a consequence, the health of the Saudi population has greatly improved in recent decades. However, a number of issues pose challenges to the health care system, such a shortage of Saudi health professionals, the health ministry's multiple roles, limited financial resources, changing patterns of disease, high demand resulting from free services, an absence of a national crisis management policy, poor accessibility to some health care facilities, lack of a national health information system, and the underutilization of the potential of electronic health strategies. This paper reviews the historical development and current structure of the health care system in Saudi Arabia with particular emphasis on the public health sector and the opportunities and challenges confronting the Saudi health care system.

\section{Aperçu du système de santé en Arabie saoudite}

RÉSUMÉ Le gouvernement d'Arabie saoudite a accordé une priorité élevée au développement des services de soins de santé à tous les niveaux : primaire, secondaire et tertiaire. En conséquence, la santé de la population saoudienne s'est grandement améliorée au cours des dernières décennies. Toutefois, le système de santé est confronté à de multiples défis tels que la pénurie de professionnels de santé saoudiens, les rôles multiples du ministère de la Santé, des ressources financières limitées, l'évolution des tableaux de morbidité, la forte demande générée par la gratuité des services, l'absence de politique nationale de gestion des crises, l'accès médiocre à certains établissements de soins, l'absence de système national d'information sanitaire et la sous-utilisation du potentiel des stratégies de cybersanté. Le présent article passe en revue l'histoire du système de santé saoudien et sa structure actuelle et met l'accent sur le secteur de la santé publique, les opportunités qui s'offrent à ce système et les obstacles auxquels il est confronté.

${ }^{7}$ College of Health Sciences, University of Jazan, Jazan, Saudi Arabia (Correspondence to M. Almalki: mohammed.almalki@gmail.com). ${ }^{2}$ Faculty of Health, School of Public Health, Queensland University of Technology, Brisbane, Australia.

Received: 28/12/08; accepted: 05/01/10 


\section{Introduction}

Health care services in Saudi Arabia have been given a high priority by the government. During the past few decades, health and health services have improved greatly in terms of quantity and quality. Gallagher has stated that: "Although many nations have seen sizable growth in their health care systems, probably no other nation (other than Saudi Arabia] of large geographic expanse and population has, in comparable time, achieved so much on a broad national scale, with a relatively high level of care made available to virtually all segments of the population (p. 182)." [1]

According to the World Health Organization (WHO) [2], the Saudi health care system is ranked 26th among 190 of the world's health systems. It comes before many other international health care systems such as Canada (ranked 30), Australia (32), New Zealand (41), and other systems in the region such as the United Arab Emirates (27), Qatar (44) and Kuwait (45). Despite these achievements, the Saudi health care system faces many challenges which require new strategies and policies by the Saudi Ministry of Health $(\mathrm{MOH})$ as well as effective cooperation with other sectors.

This review outlines the historical development and current structure of the Saudi health care system. A particular emphasis has been given to the public health sector that is operated by the $\mathrm{MOH}$, including the key opportunities and challenges it faces. In addition, this review highlights demographic changes and the economic context of Saudi Arabia in relation to the Saudi health care system.

\section{Demographic and economic patterns of Saudi Arabia}

The last official census in 2010 placed the population of Saudi Arabia at 27.1 million, compared with 22.6 million in 2004 [3]. The annual population growth rate for 2004 to 2010 was 3.2\% per annum [3], and the total fertility rate was 3.04 [4]. Saudi citizens comprise around $68.9 \%$ of the total population; $50.2 \%$ are males and $49.8 \%$ females [3]; $67.1 \%$ of the population are under the age of 30 years and about $37.2 \%$ are under 15 years; the population over the age of 60 years is estimated at $5.2 \%$ [5]. According to United Nation projections, it is estimated that the population of Saudi Arabia will reach 39.8 million by 2025 and 54.7 million by 2050 [6]. This is a natural outcome of the high birth rate (23.7 per 1000 population), increased life expectancy ( 72.5 years for men, 74.7 years for women) [4] and declining mortality rate among infants and children [1]. The under 5 years of age mortality rate fell 250 per 1000 live births in 1960 [7] to 20.0 per 1000 in 2009 [4]. Apart from advancements in health care and social services, these improved statistics can mostly be attributed to the compulsory childhood vaccination programme implemented by the government since 1980 [7]. This unprecedented growth will increase the demand for essential services and facilities including health care, while at the same time creating economic opportunities.

Saudi Arabia is one of the richest and fastest growing countries in the Middle East. It is the world's largest producer and exporter of oil, which constitutes the major portion of the country's revenues $[8,9]$. In recent decades, however, Saudi Arabia has diversified its economy, and today produces and exports a variety of industrial goods all over the world. The sound economy and well-established industry base affects the Saudi community by increasing their income, leading to a per capita income of US\$24 726 in 2008 [10] compared with US\$22935 in 2007, US\$ 14724 in 2006, US\$ 13639 in $2005[11,12]$ and US\$ 8140 in 2000 [13]. Based on 2010 information, Saudi Arabia is ranked at a high level in the Human Development Index
(0.75), which gives the country a rank of 55 out of 194 countries [10]. The improvement in the national income is expected to impact positively on its various services including the health care services.

\section{Brief overview of health services development}

Health services in Saudi Arabia have increased and improved significantly during recent decades [14]. The first public health department was established in Mecca in 1925 based on a royal decree from King Abdulaziz [15]. This department was responsible for sponsoring and monitoring free health care for the population and pilgrims through establishing a number of hospitals and dispensaries. While it was an important first step in providing curative health services, the national income was not sufficient to achieve major advances in health care, the majority of people continued to depend on traditional medicine and the incidence of epidemic diseases remained high among the population and pilgrims [15]. The next crucial advance was the establishment of the MOH in 1950 under another royal decree [15]. Twenty years later, the 5-year development plans were introduced by the government to improve all sectors of the nation, including the Saudi health care system [16]. Since then, substantial improvements in health care have been achieved in Saudi Arabia.

\section{Current structure of health services}

Currently the $\mathrm{MOH}$ is the major government provider and financer of health care services in Saudi Arabia, with a total of 244 hospitals (33277 beds) and 2037 primary health care (PHC) 
centres [4]. These services comprise $60 \%$ of the total health services in Saudi Arabia [4]. The other government bodies include referral hospitals (e.g. King Faisal Specialist Hospital and Research Centre), security forces medical services, army forces medical services, $\mathrm{Na}$ tional Guard health affairs, Ministry of Higher Education hospitals (teaching hospitals), ARAMCO hospitals, Royal Commission for Jubail and Yanbu health services, school health units of the Ministry of Education and the Red Crescent Society. With the exception of referral hospitals, Red Crescent Society and the teaching hospitals, each of these agencies provides services to a defined population, usually employees and their dependants. Additionally, all of them provide health services to all residents during crises and emergencies [16].
Jointly, the government bodies operate 39 hospitals with a capacity of 10 822 beds [4]. The private sector also contributes to the delivery of health care services, especially in cities and large towns, with a total of 125 hospitals (11 833 beds) and 2218 dispensaries and clinics (Figure 1) [4].

The advancement in health services, combined with other factors such as improved and more accessible public education, increased health awareness among the community and better life conditions, have contributed to the significant improvements in health indicators mentioned earlier. It has been noted, however, that despite the multiplicity of health service providers there is no coordination or clear communication channels among them, resulting in a waste of resources and duplication of effort
[17]. For example, there are considerable opportunities to take advantage of equipment, laboratories, training aids and well-trained personnel from different countries. However, as a result of poor coordination, the benefit of these opportunities is limited within each sector. In order to overcome this and to provide the population with up-to-date, equitable, affordable, organized and comprehensive health care, a royal decree in 2002 led to the establishment of the Council of Health Services, headed by the Minster of Health and including representatives of other government and private health sectors [18]. Although the aim of the Council was to develop a policy for coordination and integration among all health care services authorities in Saudi Arabia [19], significant progress has yet to be achieved in this area [20].

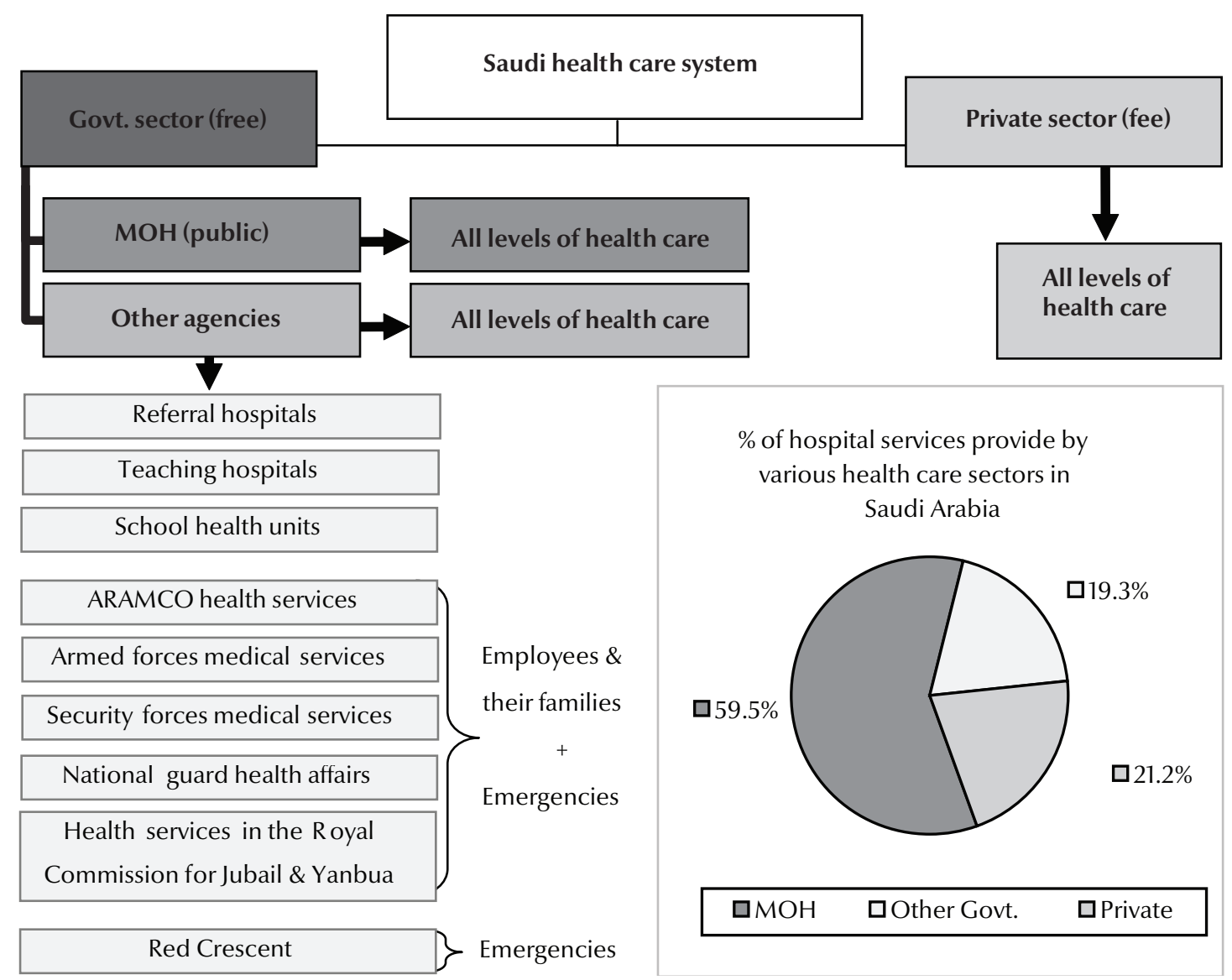

Figure 1 Current structure of the health care sectors in Saudi Arabia (MOH = Ministry of Health). Source of data: [4] 


Public health care
system (Ministry
of Health)

In accordance with the Saudi constitution, the government provides all citizens and expatriates working within the public sector with full and free access to all public health care services $[7,21]$. Government expenditure on the $\mathrm{MOH}$ increased from $2.8 \%$ in 1970 [18] to $6 \%$ in 2005 and $6.2 \%$ in 2009 (Table 1) [4]. According to $\mathrm{WHO}$ the total expenditure on public health during 2009 was 5\% of gross domestic product [22]. The MOH is responsible for managing, planning and formulating health policies and supervising health programmes, as well as monitoring health services in the private sector [23]. It is also responsible for advising other government agencies and the private sector on ways to achieve the government's health objectives [16].

The $\mathrm{MOH}$ supervises 20 regional directorates-general of health affairs in various parts of the country [18]. Each regional health directorate has a number of hospitals and health sectors and every health sector supervises a number of PHC centres. The role of these $20 \mathrm{di}$ rectorates includes implementing the policies, plans and programmes of the $\mathrm{MOH}$; managing and supporting $\mathrm{MOH}$ health services; supervising and organizing private sector services; coordinating with other government agencies; and coordinating with other relevant bodies [23]. Figure 2 illustrates the organizational structure and the relationship of departments within the Saudi health care system from the community to $\mathrm{MOH}$ level. "Health friends" is a selective committee consisting of useful and influential community members, including representatives from PHC centres, who are knowledgeable about common social norms and the potential of the community. The essential role of this committee is to liaise between PHC centres and the communities they serve $[24,25]$.

\begin{tabular}{|c|c|c|c|}
\hline Year & Government budget $\left(\mathrm{SR}^{\mathrm{a}}\right)$ & MOH budget (SR) & $\%^{\mathrm{b}}$ \\
\hline 2005 & 280000000 & 16870750 & 6.0 \\
\hline 2006 & 335000000 & 19683700 & 5.9 \\
\hline 2007 & 380000000 & 22808200 & 6.0 \\
\hline 2008 & 450000000 & 25220200 & 5.6 \\
\hline 2009 & 475000000 & 29518700 & 6.2 \\
\hline
\end{tabular}

Source: [4].

${ }^{a} U S \$ 1=3.75 \mathrm{SR} ;{ }^{b}$ As a \% of the total government budget. $S R=$ Saudi riyals

\section{Levels of health care services}

The $\mathrm{MOH}$ provides health services at 3 levels: primary, secondary and tertiary [4]. PHC centres supply primary care services, both preventive and curative, referring cases that require more advanced care to public hospitals (the secondary level of care), while cases that need more complex levels of care are transferred to central or specialized hospitals (the tertiary level of health care).

\section{Transition to PHC services}

Until the 1980s, in line with the expectations of population, health services in Saudi Arabia were largely curative, emphasizing the provision of treatment for existing health problems $[18,23]$. The curative care model, however, can be costly to health providers, when many diseases can be prevented or minimized through developing a preventive strategy. A variety of preventive measures were run by the $\mathrm{MOH}$ through former health offices and to some extent through maternal and child health care centres. A number of disease control activities were performed by vertical programmes, e.g. malaria, tuberculosis and leishmaniasis control $[18,23]$.

In accordance with the Alma-Ata declaration at the WHO General Assembly in 1978 [26], the Saudi MOH decided to activate and develop the preventive health services by adopting the PHC approach as one of its key health strategies. Consequently, in 1980, a ministerial decree was issued to establish PHC centres. The first step was to establish suitable premises throughout the country. Existing facilities located in adjacent areas were integrated into single units. These included former health offices, maternal and child health centres and dispensaries. The health posts in small and rural districts were upgraded to PHC centres $[18,23]$. The health centres aimed to focus on the 8 elements of the PHC approach: educating the population concerning prevailing health problems and the methods of preventing and controlling them; provision of adequate supply of safe water and basic sanitation; promotion of food supply and proper nutrition; provision of comprehensive maternal and child health care; immunization of children against major communicable diseases; prevention and control of locally endemic diseases; appropriate treatment of common diseases and injuries; and provision of essential drugs $[24,25]$.

Focusing on a PHC strategy and applying a logical referral system has helped to reduce the number of visits to outpatient clinics [23]. About 82\% of client visits to $\mathrm{MOH}$ facilities during 2009 were to PHC centres comprising more than 54 million PHC clients [4]. The creation of individual and family health records inside each PHC centre has reduced duplication of consultations. The use of the essential drugs list and documentation of prescriptions in patient health files has not only reduced the costs of medications, but also improved prescribing practices. 


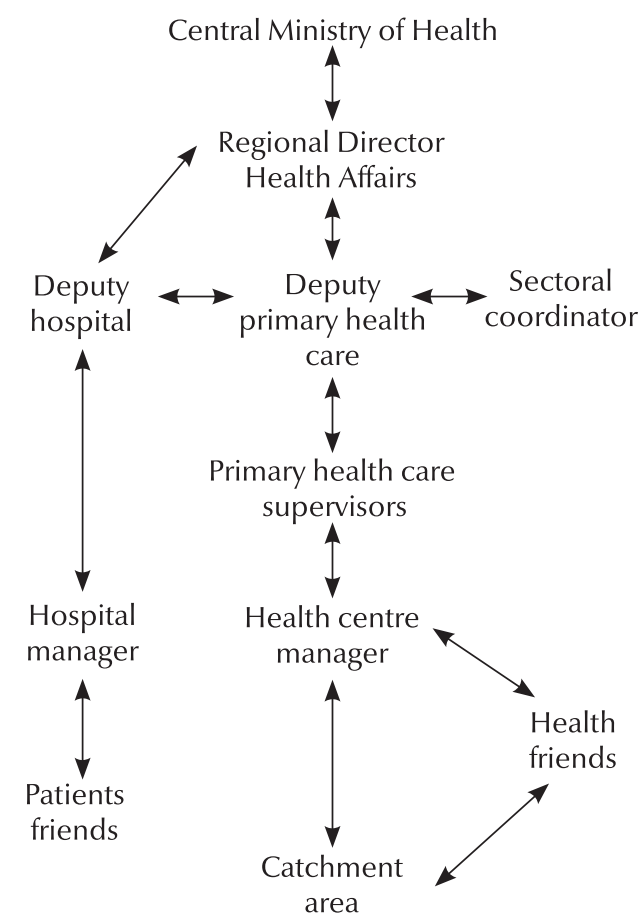

Figure 2 Organizational structure of the Ministry of Health (public) health care system in Saudi Arabia. Source: [23]

In recent years, the $\mathrm{MOH}$ has continued to develop the number of PHC centres (Figure 3) and has initiated further projects aimed at developing health care in general and PHCs in particular. For example, the project of the Custodian of the Two Holy Mosques aims to establish 2000 advanced PHC centres, and to develop the existing ones in terms of buildings, workforce and services.

\section{Health services in the pilgrimage (hajj) season}

Saudi Arabia has a unique position in the Islamic world, as it embraces the 2 holiest cities of Islam, Mecca and Medina. About 2 million pilgrims from all over the world perform the hajj annually. During the 2009 season, there were 2.3 million pilgrims, $69.8 \%$ of whom came from foreign countries [4]. Hosting such an event annually is a major challenge that requires a planned and organized effort across numerous agencies and departments to ensure adequate essential services, such as housing, transport, safety and health care [21].
Healthcareservicesin the hajjseason provide preventive and curative care for all pilgrims, irrespective of their nationality. Preventive care includes health education programmes, vaccination and chemoprophylaxis for all pilgrims via quarantine services at airports and land ports. The provision of emergency and curative services takes place through a network of health care facilities. For example, in 2009, there were 21 hospitals, of which 7 were seasonal, with a total of

3408 beds and 176 beds for emergency admissions. There were also $157 \mathrm{PHC}$ centres, of which 119 were seasonal. On average, each PHC centre treated 4734 pilgrims. The total workforce recruited to work in these facilities during 2009 was 17 886; an increase of 5\% on the previous year. Of these, $69 \%$ were physicians, nurses and allied health personnel [4]. On average, each physician treated about 612 pilgrims, while each nurse treated about 372 .

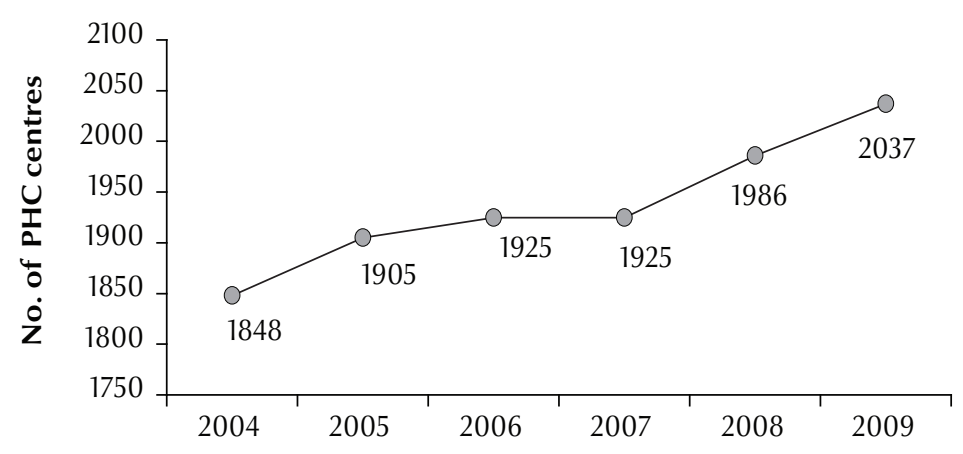

Figure 3 Trends in the number of primary health care (PHC) centres in the Ministry of Health in Saudi Arabia, 2004-09. Source: [4] 


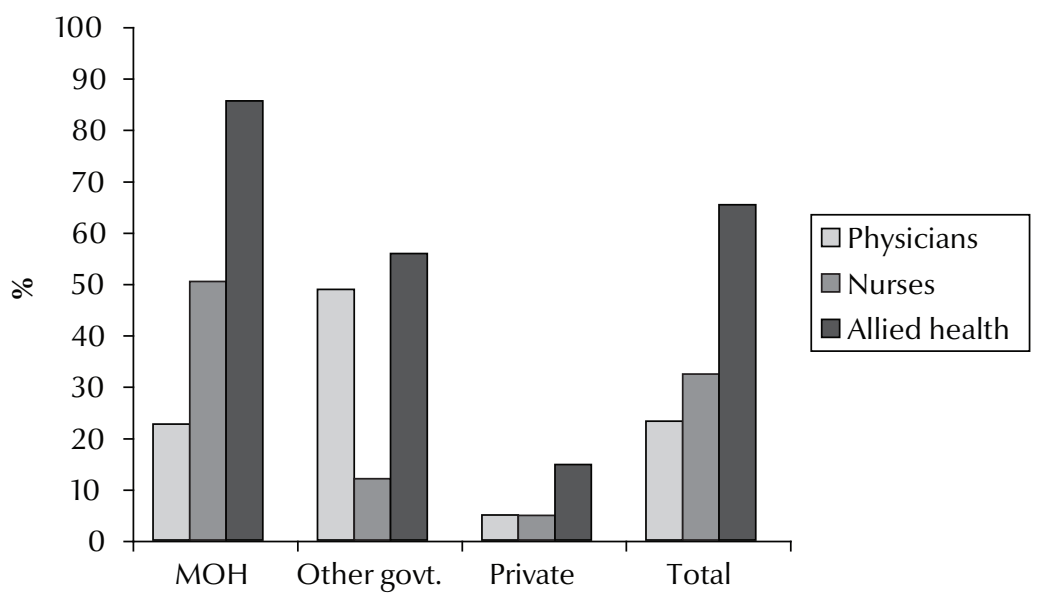

Figure 4 Distribution of Saudi health personnel in the Ministry of Health $(\mathrm{MOH})$, other government and private health care sectors in Saudi Arabia, 2009. Source: [4]

Every year, the Saudi health care agencies, particularly the $\mathrm{MOH}$, seek to improve the health care services to pilgrims [21]. Nevertheless, the fact that all the services are provided free of charge for all pilgrims is creating considerable pressure on the health care budget and it may be necessary to seek ways to provide better services at a lower cost. One suggestion is to introduce a seasonal health insurance for all international pilgrims.

\section{Challenges for health care reform}

While many steps have been undertaken by the $\mathrm{MOH}$ to reform the Saudi health care system, a number of challenges remain. These relate to the health workforce, financing and expenditure, changing patterns of diseases, accessibility to health care services, introducing the cooperative health insurance scheme, privatization of public hospitals, utilization of electronic health (e-health) strategies and the development of a national system for health information.

\section{Health workforce}

The Saudi health care system is challenged by the shortage of local health care professionals, such as physicians, nurses and pharmacists. The majority of health personnel are expatriates and this leads to a high rate of turnover and instability in the workforce [27]. According to the $\mathrm{MOH}$ the total health workforce in Saudi Arabia, including all other sectors, is about 248 000; more than half of them (125 000) work in the $\mathrm{MOH}$ [4]. Saudis constitute 38\% of this total workforce. Of these, $23.1 \%$ are physicians, while $32.3 \%$ are nurses (Figure 4). In the MOH, Saudis constitute about $54 \%$ of the health workforce, (physicians 22.6\% and nurses 50.3\%). The rates of physicians and nurses in Saudi Arabia are 16 and 36 respectively per 10000 population, lower than in other countries such as Bahrain (30 and 58 per 10000 ), Kuwait (18 and 37 per 10 000), Japan (12 and 95 per 10000 ), Canada (19 and 100 per 10000 ), France (37 and 81 per 10000 ) and the United States of America (27 and 98 per 10000$)$ [28].

The ability to formulate and apply practical strategies to retain and attract more Saudis into the medical and health professions, particularly nursing, is a clear priority for effective reform of the Saudi health care system. Many efforts have been taken by the government to teach and train Saudis for health professional jobs. Since 1958, a number of medical, nursing and health schools have been opened around the nation to meet this goal [7]. Apart from private colleges and institutes, there are a total of $73 \mathrm{col}-$ leges for medicine, health and nursing as well as 4 health institutes in Saudi Arabia [4]. Efforts to establish such colleges are in accordance with training programmes that aim to substitute the largely expatriate workforce with qualified Saudi Arabian nationals in all sectors, including health $[18,29]$. The budget allocation for training and scholarships has increased and many $\mathrm{MOH}$ employees are offered a chance to pursue their studies abroad [18]. This strategy could improve the skills of current employees, raise the quality of health care and, it is hoped, decrease the rate of turnover among health professionals. However, these efforts may not be enough to solve the challenges. The proportion of Saudi Arabian health professionals in the $\mathrm{MOH}$ workforce is expected to decrease in the future as the expansion in health care facilities around the country has the effect of spreading a scare resource even more thinly $[17,30]$. 
More realistic plans and long-term strategies need to be consolidated by the $\mathrm{MOH}$ in cooperation with government and private sectors. A good example of such cooperation is the King Abdullah international scholarship programme which was established by the Ministry of Higher Education. In its stage 4 , priority has been given to medical specialists including medicine, nursing, pharmacy and other health majors [31]. However, more medical colleges and training programmes need to be established around the country. New laws and regulations to develop and reorganize medical human resources by the $\mathrm{MOH}$ are urgently required.

\section{Reorganization and restructuring of the $\mathrm{MOH}$}

The public health sector is overwhelmingly financed, operated, controlled, supervised and managed by the $\mathrm{MOH}$ [32]. This model of management may not able to meet the population's health care needs into the future unless serious and well-planned steps are taken to separate these multiple roles. Possible solutions include giving more authority to the regional directorates, applying the cooperative health insurance scheme and encouraging the privatization of public hospitals.

\section{Decentralization of health services and autonomy of hospitals}

To meet increasing pressure on the $\mathrm{MOH}$, more autonomy has been given to the regional directorates in terms of planning, recruitment of professional staff, formulating agreements with health services providers (operating companies) and some limited financial discretion. It has been suggested that the functioning of the regional directorates is adversely affected by the lack of individual budgets and spending authority [16]. Expenditure for the majority of their activities must be authorized by the $\mathrm{MOH}$, thus affecting the autonomy of regional directorates and hampering effective decision-making.
In terms of hospital autonomy, the $\mathrm{MOH}$ has tried a number of strategies for improving the management of public hospitals during past decades, including direct operation by the $\mathrm{MOH}$, cooperation with other governments such the Netherlands, Germany and Thailand, partial operation by health care companies, comprehensive operation by health care companies and the autonomous hospital system [33]. Considering the advantages and disadvantages of these approaches, the $\mathrm{MOH}$ has standardized an autonomous hospital system for 31 public hospitals in various regions [34]. The autonomous hospital system for public hospitals is expected to raise the efficiency of their performance in both medical and managerial functions, achieve financial and administrative flexibility through adopting a direct budget strategy, apply quality insurance programmes and simplify the contractual process with qualified health professionals [33]. In 2009, the $\mathrm{MOH}$ issued new regulations for self-operating public hospitals to ensure a high level of management practices and to improve the quality of services provided [35]. Giving more autonomy to hospitals will help the transition to full privatization of public hospitals in Saudi Arabia. It gives public hospitals more experience in the management of their budgets, health care quality and workforce.

\section{Health insurance in Saudi Arabia}

Funding health care services is a central challenge faced by the $\mathrm{MOH}$ [32]. Since the total expenditure on public health services comes from the government and the services are free-of-charge, this lead to considerable cost pressure on the government, particularly in view of the rapid growth in the population, the high price of new technology and the growing awareness about health and disease among the community [14]. To meet the growing population demands for health care and to ensure the quality of services provided, the Council for Cooperative Health Insurance was established by the government in 1999 [19]. The main role of this Council is to introduce, regulate and supervise a health insurance strategy for the Saudi health care market.

The implementation of a cooperative health insurance scheme was planned over 3 stages. In the first stage, the cooperative health insurance was applied for non-Saudis and Saudis in the private sector, in which their employers have to pay for health cover costs. In the second stage, the cooperative health insurance is to be applied for Saudis and non-Saudis working in the government sector. The government will pay the cooperative health insurance costs for this category of employee. In the final stage, the cooperative health insurance will be applied to other groups, such as pilgrims [36]. Only the first stage has been implemented to date, with the cooperative health insurance being implemented gradually in a 3-phase programme to employees of the private sector and their dependants $[14,37]$. The first phase covered companies with 500 or more employees, while the second phase applied to employers with more than 100 workers. The third phase included employees of all companies in Saudi Arabia as well as domestic workers $[14,37]$. The government is now working systematically to apply the remaining 2 stages - for employees in the government sector and for pilgrimsbefore they privatize the state-owned health care facilities [14]. No information is available yet regarding the cooperative health insurance scheme for the population of Saudi Arabia other than employees and expatriates.

While the market for cooperative health insurance in Saudi Arabia started with only 1 company in 2004, it currently involves about 25 companies. The introduction of the scheme is intended to decrease the financial burden on Saudi Arabia due to the costs associated with providing health services free-of-charge. It will also give people 
more opportunity to choose the health services they require [14]. The real challenge for policy-makers in Saudi Arabia is to introduce a comprehensive, fair, and affordable service for the whole population. Clearly lessons can be learned from the experiences of other countries, including the advantages and disadvantages of different schemes.

\section{Privatization of public hospitals}

Privatization of publichospitals has been seen by policy-makers and researchers as the best way to reform the Saudi health care system $[38,39]$. Steps to implement a privatization strategy have been initiated and related regulation has been passed by the government. As a result, a number of public hospitals are likely to be sold or rented to private firms over the next few years [14]. Privatization of hospitals is expected to bring a number of advantages to the government and to the nation. It is hoped that privatization will assist in speeding up decision-making, reducing the government's annual expenditure on health care, producing new financial sources for the $\mathrm{MOH}$ and improving health care services [38].

On the other hand, privatization may affect the current integrated system between hospitals and PHC facilities [14]. As hospitals become privatized, they will focus on attracting patients, even those who may not require hospital-level care. Moreover, people with health cover may prefer to access big hospitals directly instead of via PHC centres or community hospitals. Additionally, private hospitals will have incentives to shift non-refundable costs back to the public PHC [14]. Such practices will place financial burdens on the government.

A further drawback of privatization is that the traditional state/public hospitals will not be able to absorb enough of the health care market compared with private companies, unless they upgrade at all levels (e.g. management, infrastructure and workforce) before starting to privatize [14]. In the move to privatization, private companies are likely to focus their activities within cities and larger communities, leaving people in rural areas at a disadvantage. The government should set regulations that protect the rights of rural communities and provide them with fair and equitable health care services.

Finally, if the government does not apply adequate control over the health care market, expenditure on health care may increase dramatically as a result of higher pricing and profit-seeking behaviour [14]

\section{Accessibility to health services}

Optimizing the accessibility of health care services requires equity in the distribution of health care facilities throughout the nation and equity of access to health professionals, including transport to services and providers. Accessibility is also affected by the level of cooperation between related sectors $[23,39]$. The current $\mathrm{MOH}$ statistics indicate that there is a maldistribution of health care services and health professionals across geographical areas [4]. People experience long waiting lists for many health care services and facilities [14]. Additionally, there is a dearth of services for disadvantaged groups such as the elderly, adolescents and people with special needs such as disability, particularly in rural areas [39]. Finally, many people do not have the ability to access health care facilities, particularly those living in border and remote areas.

In order to improve accessibility to health care services in all parts of the country, aholisticstrategy for theredistribution of health care services, involving PHC centres, general hospitals, central and specialist hospitals as well as the health professionals, should be adopted by the $\mathrm{MOH}$. The $\mathrm{MOH}$ should also liaise with other sectors such transport, water and power companies and social security services in order to develop services in deprived areas and to care for people with the greatest needs.

\section{Patterns of diseases}

The change in disease patterns from communicable to noncommunicable diseases in Saudi Arabia is another challenge that needs more attention from the $\mathrm{MOH}$ [21]. There has been an alarming increase in the prevalence of chronic diseases, such as diabetes, hypertension, and heart diseases, cancer, genetic blood disorders and childhood obesity $[28,40,41]$. Treatment of chronic diseases is costly and may even be ineffective [40]. For example, the annual cost for treatment of diabetes mellitus in Saudi Arabia was estimated to be 7 billion Saudi riyal (SR) (US\$ 1.87 billion) [42]. Early prevention is the most effective way to reduce the prevalence of chronic diseases and the costs and difficulties associated with treatment in the later stages of disease. Any projected reforms in the health care system must involve plans to address this change in emphasize.

\section{Promotion and prevention programmes for crises}

Development and implementation of practical plans and procedures to meet national crises in Saudi Arabia, such as wars, earthquakes and fires and explosions at petroleum factories, are a further important need. Road traffic accidents, for example, killed more than 39 000 and injured about 290000 people between 1995 and 2004 [43]. According to WHO, road traffic accidents are now the highest cause of death, injury and disability in adult males aged 16 to 36 years in Saudi Arabia [32]. Caring for people affected by road accidents consumes a significant proportion of the $\mathrm{MOH}$ budget; for example, the cost of treating injured people during 2002 was estimated to be SR 652.5 million (US\$ 174 million) [43]. These funds could be used to develop the health system and improve services. Plans to manage issues of this kind need to be comprehensive and well-coordinated among the related sectors in order to be achievable. 


\section{e-health and national health information systems}

There is increasing concern about the underutilization of electronic health systems in Saudi Arabia. Implementation of e-health and electronic information systems has already started in a number of hospitals and organizations such as the King Faisal specialist hospital and research centre, national guard health affairs, medical services of the army forces and university hospitals [44]. While uptake of e-health systems is moving slowly in $\mathrm{MOH}$ institutions, there are a number of information systems operating in the regional directorates and in central hospitals. Unfortunately, these information systems are not connected to each other or to other private or specialized health organizations [44].

To develop e-health services in the public sector, a budget of SR 4 billion (US\$ 1.1 billion) was allocated by the $\mathrm{MOH}$ to run a 4-year development programme (2008-11) [45]. Additionally, a series of conferences on e-health have been held by the Saudi Association for Health Information to emphasize the importance of e-health in enhancing the quality of health care delivery and to explore the necessary strategies, policies, applications and infrastructure [46].

More coordination among different health care providers is needed in order to enhance the use of e-health strategies and to launch a comprehensive national system for health information. A high level of coordination must be achieved with other related sectors to provide the required infrastructure such as internet and phone services.

\section{New strategy for health care services}

To meet the challenges of the Saudi health care system and to improve the quality of health care services, the $\mathrm{MOH}$ has set a national strategy for health care services. This strategy was approved by the Council of Ministers in April 2009. It focuses on diversifying funding sources; developing information systems; developing the human workforce; activating the supervision and monitoring role of the $\mathrm{MOH}$ over health services; encouraging the private sector to take its position in providing health services; improving the quality of preventive, curative and rehabilitative care; and distributing health care services equally to all regions.

The national strategy for health care services is to be implemented by the $\mathrm{MOH}$ in cooperation with other health care providers and it will be supervised by the Council of Health Services. A 20-year timeframe for achieving the objectives of this strategy has been identified [39].

\section{Conclusion}

As a result of the continued attention to and support from the government,
Saudi health services have advanced greatly over recent years in all levels of health services: primary, secondary and tertiary. As a consequence, the health of the Saudi population has improved markedly. The $\mathrm{MOH}$ has introduced many reforms to its services, with substantial emphasis on PHC.

Despite these achievements, health services, and in particular public sector health services, are still facing many challenges. These include: human resource development; separation of the MOH's multiple roles (financing, provision, control and supervision of health care delivery); diversifying financial sources; implementing the cooperative health insurance, privatization of public hospitals, effective management of chronic diseases; development of practical policies for national crises; establishment of an efficient national health information system and the introduction of e-health. In order to address these challenges and continue to improve the status of the Saudi health care system, the $\mathrm{MOH}$ and other related sectors should coordinate their efforts to implement and ensure the success of the new health care strategy.

\section{Acknowledgements}

This paper is part of the first author's doctoral research, supported by the government of Saudi Arabia.

\section{References}

1. Gallagher EB. Modernization and health reform in Saudi Arabia, Chapter 4. In: Twaddle AC, ed. Health care reform around the world. London, Auburn House, 2002:181-197.

2. The world health report 2000. Health systems: improving performance. Geneva, Word Health Organization, 2000.

3. Keyindicators. Central Department of Statistics and Information, Saudi Arabia [online database] (http://www.cdsi.gov.sa/ english, accessed 27 June 2011).

4. Health statistical year book. Riyadh, Saudi Arabia, Ministry of Health, 2009.

5. Statistical year book 45. Riyadh, Saudi Arabia, Central Department of Statistics and Information, 2009.

6. World population 2002. New York, United Nations, 2003.
7. Aldossary A, While A, Barriball L. Health care and nursing in Saudi Arabia. International Nursing Review, 2008, 55:125-128.

8. Profile research: Kingdom of Saudi Arabia. Oil and Gas Directory Middle East [online factsheet] (http://www. oilandgasdirectory.com/research/Saudi.pdf, accessed 27 June 2011).

9. Exports of Saudi Arabia: the main commodities. Riyadh, Saudi Arabia, Ministry of Finance, 2010.

10. Human development report 2010.The real wealth of nations: Pathways to human development. New York, United Nations, 2010.

11. Human development report 2009. Overcoming barriers: Human mobility and development. New York, United Nations, 2009. 
12. General statistics. Riyadh, Saudi Arabia, Ministry of Economy and Planning, 2007.

13. Saudi Arabia. Data. The World Bank [online database] (http:// data.worldbank.org/country/saudi-arabia, accessed 15 June 2011).

14. Walston S, Al-Harbi Y, Al-Omar B. The changing face of healthcare in Saudi Arabia. Annals of Saudi Medicine, 2008, 28:243250.

15. Alharthi F et al. Health over a century. Riyadh, Ministry of Health and ASBAR Centre for Studies Research and Communication, 1999.

16. Mufti MHS. Healthcare development strategies in the Kingdom of Saudi Arabia. New York, Kluwer Academic/Plenum, 2000.

17. Alhusaini HA. [Obstacles to the efficiency and performance of Saudi nurses at the Ministry of Health, Riyadh Region: analytical field study]. Riyadh, Saudi Arabia, Ministry of Health, 2006 [in Arabic].

18. Health system profile. Saudi Arabia. World Health Organization Eastern Mediterranean Regional Health System Observatory [online database]. (http://gis.emro.who.int/HealthSystemObservatory/Profile/Forms/frmProfileSelectionByCountry.aspx? CountryID=SAP000000000000000000\&Country Name $=$ Sa udia\%20Arabia, accessed 15 June 2011).

19. [Vision and tasks of the Council of Health Services in Saudi Arabia] Council of Health Services [website] (http://www.chs.gov.sa/ COHS/default.aspx, accessed 15 June 2011) [in Arabic]

20. Alkhazem M. [Health coordination starts from the Ministry]. Al Riyadh Daily. 12 April 2009 [in Arabic].

21. Jannadi B et al. Current structure and future challenges for the healthcare system in Saudi Arabia. Asia Pacific Journal of Health Management, 2008, 3:43-50.

22. Countries: Saudi Arabia. Word Health Organization [website] (http://www.who.int/countries/sau/en/, accessed 15 June, 2011).

23. Al-Yousuf M, Akerele TM, Al-Mazrou YY. Organization of the Saudi health system. Eastern Mediterranean Health Journal, 2002, 8:4-5.

24. Al Mazrou Y, Al-Shehri S, Rao M. Principles and practice of primary health care. Riyadh, Saudi Arabia, Ministry of Health, 1990.

25. Al Mazrou Y, Salem AM. [Primary health care guide]. Riyadh, Saudi Arabia, Ministry of Health, 2004 [in Arabic].

26. Al-Ahmadi H. Quality of primary health care in Saudi Arabia: a comprehensive review. International Journal for Quality in Health Care, 2005, 17:331-346.

27. Saudi Arabia: country cooperation strategy: at a glance. World Health Organization [online factsheet] (http://www.who.int/ countryfocus/cooperation_strategy/ccsbrief_sau_en.pdf, accessed 15 June 2011).

28. World health statistics. Geneva, Word Health Organization, 2010

29. Tumulty G. Professional development of nursing in Saudi Arabia. Journal of Nursing Scholarship, 2001, 33:285-290.

30. Alamri AS, Rasheed MF, Alfawzan NM. [Reluctance of Saudi youth towards the nursing profession and the high rate of unemployment in Saudi Arabia: causes and effects]. Riyadh, Saudi Arabia, King Saud University, 2006 [in Arabic].

31. [Program of the Custodian of the Two Holy Mosques for studying overseas (Phase IV)]. Ministry of Higher Education, Saudi Arabia [website] (http://kas.mohe.gov.sa/kas4/indexu4.aspx, accessed 28 June 2011) [in Arabic].

32. Country cooperation strategy for WHO and Saudi Arabia 20062011. Cairo, World Health Organization Regional Office for the Eastern Mediterranean, 2007 (EM/ARD/014/E/R).

33. Al-Ateeq FA. Experience of Saudi Arabia in operation of public hospitals: the transition from companies'operating system to selfoperating system. Paper presented at the Conference on Recent Trends in the Management of Private and Public Hospitals in the Arab World, 12-14 March 2002. Cairo, Arab Administrative Development Organisation, 2002.

34. [Achievements of the Ministry of Health]. Ministry of Health, Saudi Arabia [website] (http://www.moh.gov.sa/Ministry/ MediaCenter/News/Pages/NEWS-2007-9-24-001.aspx, accessed 28 June 2011) [in Arabic].

35. Al-Zahrani S. [Requiring employees of self-operating public hospitals to work for six days per week instead of five]. AlMadinah Daily, 26 July 2009 [in Arabic].

36. Alsharif Al. Health system and insurance in Saudi Arabia. Paper presented at the Board of Healthcare Funders Southern African Annual Conference, Durban, 3-16 July 2008. Port Elizabeth, South Africa, Providence Healthcare Risk Mangers, 2008.

37. Al-Shaikh S. Saudi health care sector: need for more investment. Arab News, 7 August 2006

38. Saati A. [Privatisation of public hospitals: future vision and proposed framework]. Al-Egtisadia Daily, 2 December 2003 [in Arabic].

39. [New strategy for health services in Saudi Arabia]. Al-Egtisadia Daily, 9 September 2009 [in Arabic]

40. Al-Qurashi MM et al. The prevalence of sickle cell disease in Saudi children and adolescents: a community-based survey. Saudi Medical Journal, 2008, 29:1480-1483.

41. Al-Turki YA. Overview of chronic diseases in the Kingdom of Saudi Arabia. Saudi Medical Journal, 2000, 21:499-500.

42. [Allocation of 110 million riyals for establishment of 20 diabetes care centre]. Riyadh, Ministry of Health, 2007 (http://www. moh.gov.sa/Ministry/MediaCenter/News/Pages/NEWS2007-10-29-001.aspx, accessed 28 June 2011) [in Arabic].

43. Assaied RA. [Economic impact of traffic accidents]. Riyadh, Naif Arab University for Security Sciences, 2008 [in Arabic].

44. Altuwaijri MM. Electronic-health in Saudi Arabia: just around the corner? Saudi Medical Journal, 2008, 29:171-178.

45. Qurban MH, Austria RD. Public perception on e-health services: implications of preliminary findings of KFMMC for military hospitals in KSA. Paper presented at the European and Mediterranean Conference on Information Systems (EMCIS2008), 25-26 May 2008. Dubai, Information Systems Evaluation and Integration Group, 2008

46. Towards national e-health. Saudi e-health conference, 17-19 March 2008. Riyadh, Saudi Association for Health Informatics, 2008 (http://www.saudiehealth.org/2008/, accessed 28 June 2011). 